\title{
Discovery of the female of Pyrocoelia prolongata in Taiwan (Coleoptera, Lampyridae)
}

\author{
Ming-Luen Jeng ${ }^{1,2}$, Michael S. Engel', Ping-Shih Yang ${ }^{3}$ \\ I Division of Entomology, Natural History Museum, and Department of Ecology \& Evolutionary Biology, \\ 1501 Crestline Drive - Suite 140, University of Kansas, Lawrence, Kansas 66045, USA 2 Current address: \\ Entomology Division, Zoology Department, National Museum of Natural Science, 1, Guanqian Rd., Taichung \\ City 40453, Taiwan, ROC 3 Department of Entomology, National Taiwan University, Taipei City 106, Tai- \\ wan, $R O C$ \\ Corresponding author: Ping-Shih Yang (psyang@ntu.edu.tw)
}

Academic editor: Terry Erwin | Received 19 April 2011 | Accepted 14 June 2011 | Published 6 July 2011

Citation: Jeng M-L, Engel MS, Yang P-S (2011) Discovery of the female of Pyrocoelia prolongata in Taiwan (Coleoptera, Lampyridae). ZooKeys 116: 49-57. doi: 10.3897/zookeys.116.1412

\begin{abstract}
The female of Pyrocoelia prolongata Jeng and Lai, a diurnal lampyrid species from Taiwan, is described for the first time. A single individual was found in a small, shady, dry streambed at the edge of a mixed forest at $2700 \mathrm{~m}$ elevation. The individual glowed in darkness and would move its abdomen up and down when disturbed and as a deterring behavior. A key to the females of the species of Pyrocoelia Gorham in Taiwan is provided. The morphology of photogenic organs of females and the function of bioluminescence of day-active species of Pyrocoelia are discussed.
\end{abstract}

\section{Keywords}

Pyrocoelia prolongata, female, Taiwan, diurnal, Lampyrinae, Asia

\section{Introduction}

The genus Pyrocoelia Gorham is a group of Asian lampyrids including more than 60 known species (McDermott 1966; Jeng et al. 1999b). Males of the genus are alate while, where known, females have vestigial elytra to various degrees and lack hind wings. They can be divided into diurnal and nocturnal groups in which the males possess well-developed photogenic organs in the former but reduced in the latter. 
The nomenclature of Pyrocoelia was clarified and the species of Taiwan were revised by Jeng et al. (1999b). Several publications provided additional information and images of the females of Taiwanese species (Ho 1997; Chen 1999, 2003; Ho and Chu 2002). Until now, four out of the five species (except $P$. prolongata Jeng and Lai, a species endemic to Taiwan) have confirmed females. Generally it is difficult to find the flightless females in the field, especially for the diurnal species (Ohba 1983). Because of the limited availability and dramatic sexual dimorphism, many of the females were identified to species by rearing larvae to adults. This has not been achieved for $P$. prolongata. Fortunately a female of the species was discovered in the field during a collecting trip to high mountains in southern Taiwan in 2004. Herein we describe this individual and its remarkable bionomics, and provide a key to the females of Taiwan's species of the genus.

\section{Material and methods}

The only female specimen available for study was collected by the late Japanese coleopterist Dr. M. Satô while digging in a dry streambed for ground beetles at high elevations in southern Taiwan. The female was kept in a transparent plastic cup which was spread with wet tissue paper and moss to maintain suitable humidity and for observation.

Measurements were made by outlining the target structures under a Nikon SMZ10 microscope with a camera lucida. Body length (BL) was measured as the distance between pronotal and abdominal apices when the body was fully stretched, and body width (BW) as the greatest distance across the abdomen. The abbreviations PL and PW denote pronotal length and width, respectively; while T\#, P\#, and S\# refer to the tergite, pleurite, and sternite of the \#th abdominal segment (true segmentation), respectively.

\section{Systematics}

\section{Pyrocoelia prolongata Jeng and Lai}

http://species-id.net/wiki/Pyrocoelia_prolongata

Pyrocoelia prolongata Jeng and Lai, in Jeng et al. 1999b: 358.

Diagnosis. The female is characterized by the bell-shaped pronotum which resembles that of the male and is one of the diagnostic characters of the species (Jeng et al. 1999b). No other congeneric species from Taiwan share a similar pronotal morphology and coloration in the female. The temporal and spatial distribution also fits that of $P$. prolongata.

Description. Female (Figs 1-7): BL: $15.6 \mathrm{~mm}$; BW: $4.6 \mathrm{~mm}$. Body form elliptical and depressed. Head, antennae, and legs dark brown to black; pronotum translucent 


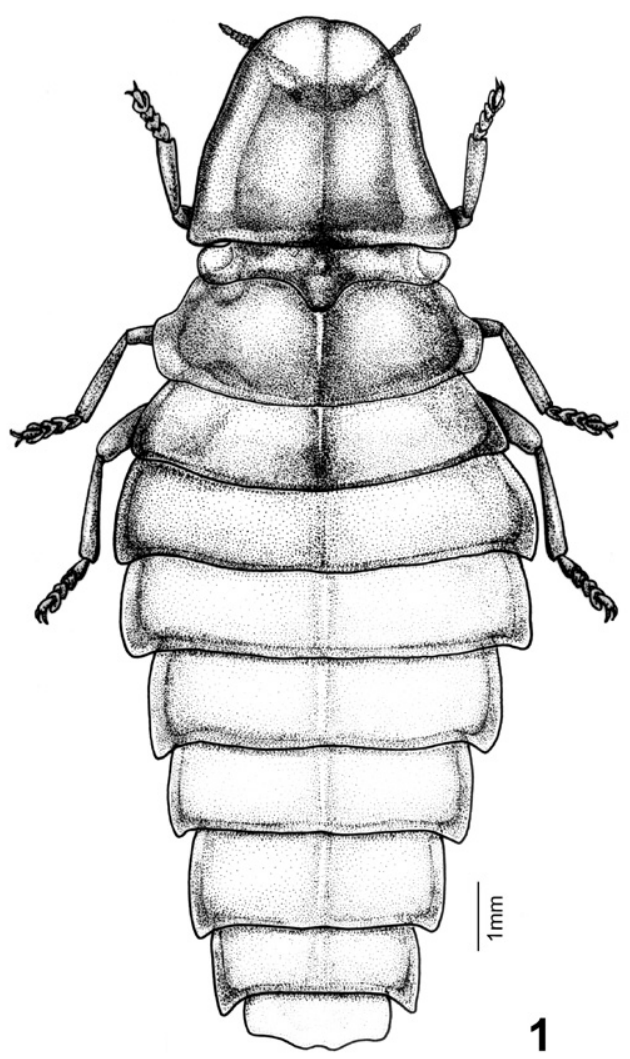

Figure I. Female dorsal habitus of Pyrocoelia prolongata Jeng and Lai.

gray, with margins and central carina light brown and central disc pink; mesonotum pink, central disc and mesoscutellum dark brown, translucent gray at sides (elytral rudiments); metanotum bronze; abdominal T1 lighter than metanotum and mixed of pink; T2-7 pinkish white, bronze on posterior margins and central line, and translucent gray at lateral margins (Fig. 7A); T8 translucent gray; ventral side pink, brightly so on thorax and pale on abdomen; 88 with a pair of milky white photogenic organs; S8-9 translucent yellowish brown. Head spherical, about 1/3 as broad as pronotum; vertex concave along central line; frons about as broad as clypeus-labrum; antennal sockets widely separated from each other; antenna (Fig. 2) 11-segmented, weakly serrate and rod-like; antennomere 1 largest and 3 slightly smaller than it; clypeus-labrum (Fig. 3) not fused with frons, shell shape; mandibles partially sclerotized, thick in basal $2 / 3$ and slender and somewhat curved at apex; maxillary palpus 4-segmented; labial palpus 3-segmented. Pronotum bell-shape, strongly convex on central disc and weakly so in windows, reflexed at margins; windows on apical $1 / 3$ and divided by central carina. $\mathrm{PL} / \mathrm{PW}=0.85$. Mesonotum as broad as central disc of pronotum, with elytral rudiments abbreviated and round at sides, not extending beyond pronotum; mesoscutel- 

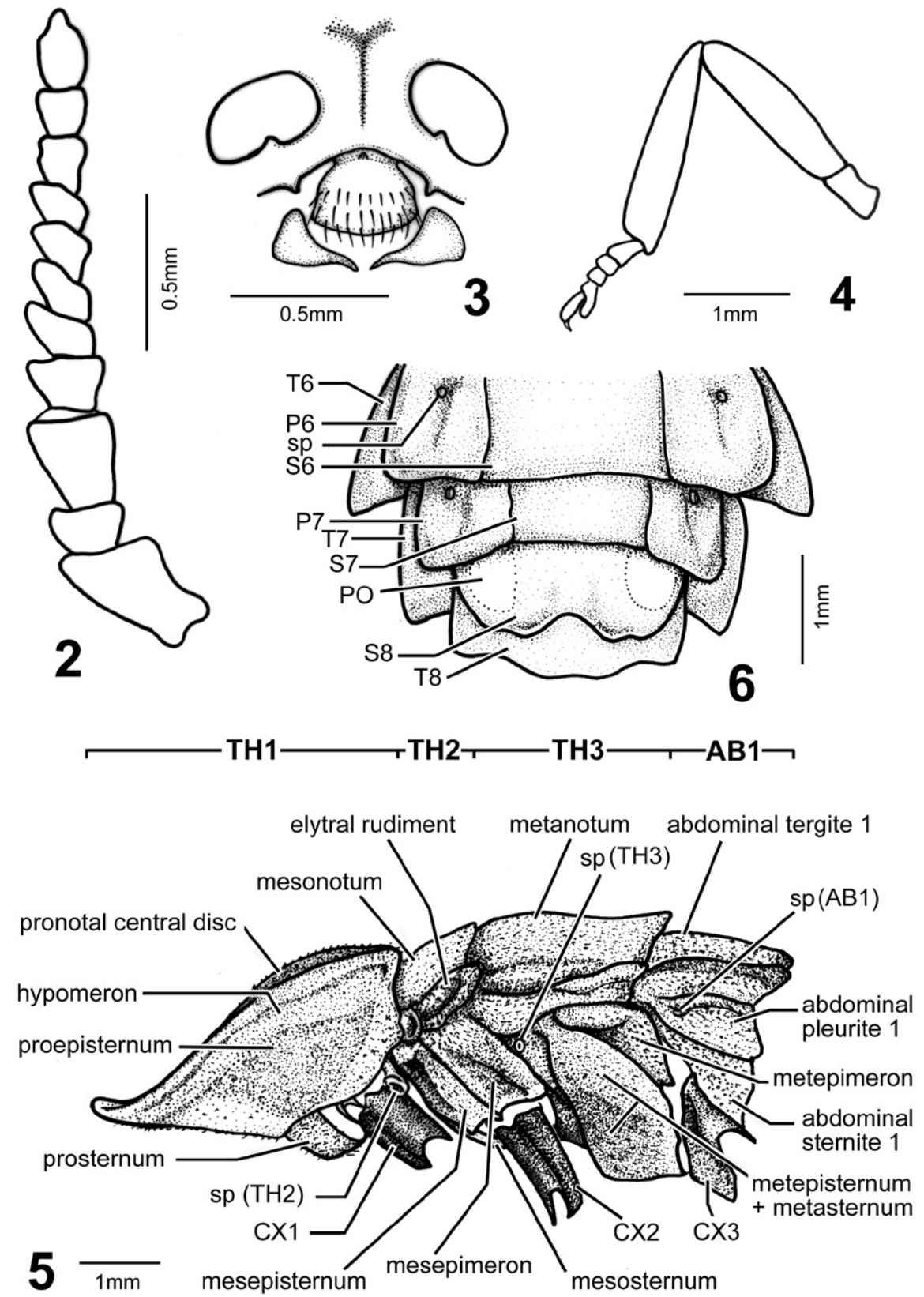

Figures 2-6. Pyrocoelia prolongata Jeng and Lai, female 2 Antenna 3 Partial head in frontal aspect (frons, antennal sockets, clypeus-labrum, and mandibles), antennae removed 4 Hind leg (metatrochanter-metatarsus) 5 Thoracic segments (TH1-3), coxae (CX1-3), and first abdominal segment (AB1), lateral aspect; sp $(\#)=$ spiracle on \#th segment $\mathbf{6}$ Abdominal segments $6-8$, ventral aspect, $\mathrm{T} \#, \mathrm{P} \#$, and $\mathrm{S \#}=$ abdominal tergite, pleurite, and sternite of \#th segment; $\mathrm{PO}=$ photogenic organs. 
lum transverse, broader than long by 2 times, with apex slightly notched. Metanotum broader than pronotum, transversely elliptical, with a concave central line. Metepisternum fused with metasternum (Fig. 5). Legs (Fig. 4) moderate in width and length, $5^{\text {th }}$ tarsomere slightly longer than preceding tarsomere. Abdomen broadest at T2, T1 about as broad as T3 and diminishing in width accordingly toward apex; T1-8 each with short but clear hind angles; T1-7 with a paler central line; T8 (Fig. 6) transverse and subquadrate, sinuate at sides and central apex. P1-7 folded on inner margins, each bearing a spiracle at center. S8 deeply notched centrally, with a pair of photogenic organs at sides (= PO, Fig. 6, Fig. 7B).

Material examined. 19, S. Taiwan: Kaohsiung County (now Kaohsiung City), Yako logging trail (abandoned), 12057’E, 2316'N, 2700m above sea level, 8.VII.2004 around midday, M. Satô leg.; specimen deposited in the collection of the senior author, National Museum of Natural Science, Taiwan.

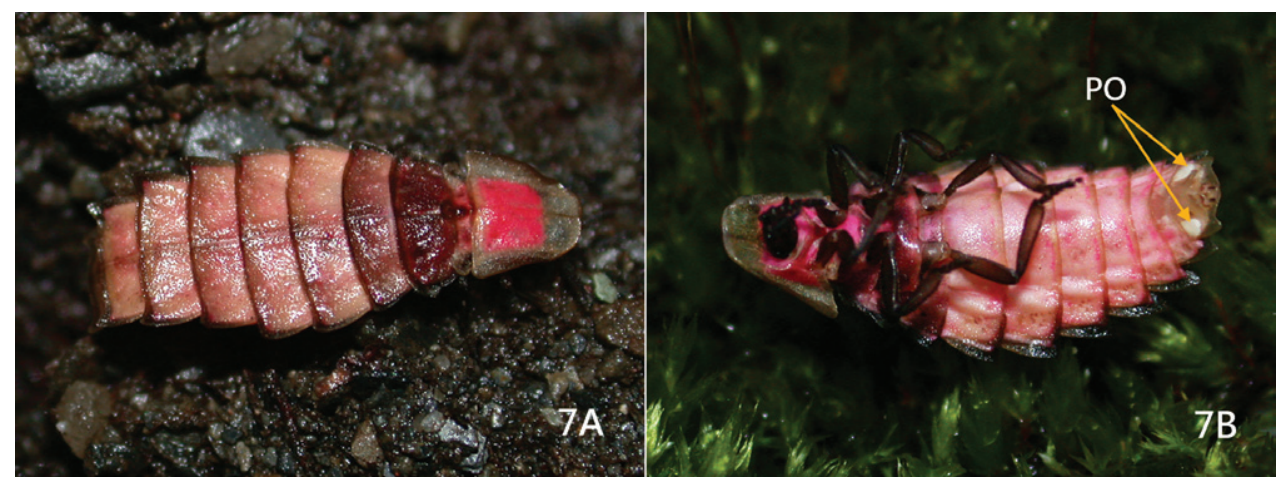

Figure 7. Photos of female of Pyrocoelia prolongata Jeng and Lai A Dorsal aspect B Ventrolateral oblique aspect. Note the pink and bronze luster on the dorsum as well as the distinct photogenic organs (PO) on the venter.

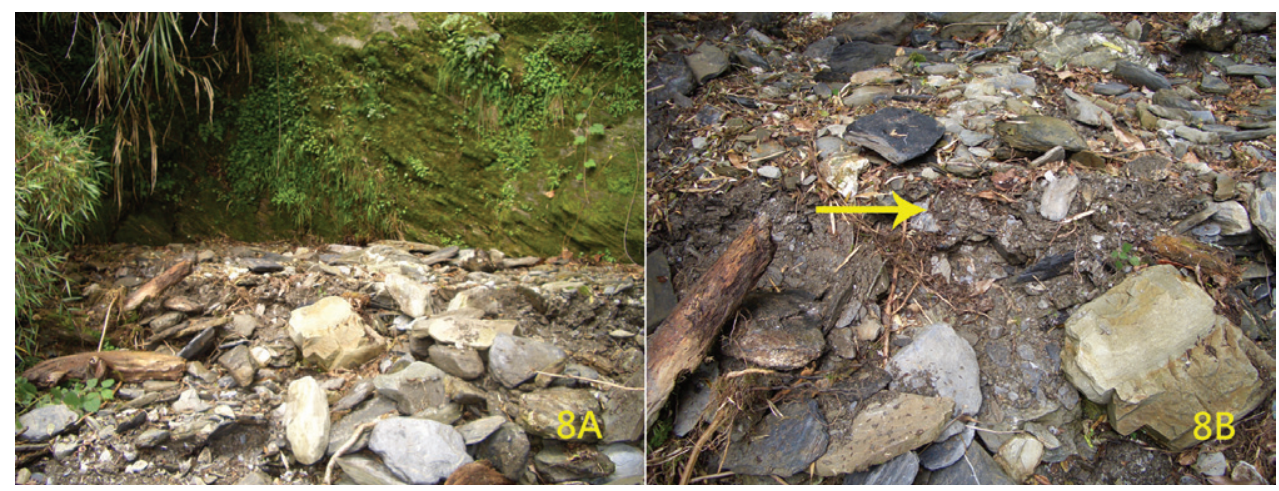

Figure 8. Habitat of Pyrocoelia prolongata Jeng and Lai female A General locality in Yako logging trail, a dry streambed at $2700 \mathrm{~m}$ above sea level, southern Taiwan B Close-up, indicating where the female was discovered (arrow). 
Sexual dimorphism. Females differ from males by (generic level differences) 1, having shorter and less serrate antennae, much smaller compound eyes, and smaller palpi; $\mathbf{2}$, the mesoscutellum as broad as long; $\mathbf{3}$, the highly abbreviated elytra and absence of hind wings; $\mathbf{4}$, the fusion of metepisternum and metasternum; 5, having an intact abdominal $S 1 ; \mathbf{6}$, having the hind angles of abdominal T1-7 not very acute; 7 , S8 being deeply emarginate (cf., Jeng et al., 1999b); 8, (remainder are species-level differences) the bronze on the metanotum and abdominal T1; and $\mathbf{9}$, the narrower dark margins on the pronotum. In contrast to known females of Pyrocoelia, the female of P. prolongata is smaller than its respective males. We are not sure if this is simply individual variation or universal to the species.

Habitat and phenology. The female was found in a small, shady, and damp dry streambed at the edge of a mixed forest dominant with Taiwan Red False Cypress [Chamaecyparis formosensis Matsumura (Cupresaceae)] (Fig. 8A). It stayed on the substrate mixed of gravel and sand under a slate stone (Fig. 8B). An Alishan salamander (Hynobius arisanensis Maki) was also found in the microhabitat. Only a few species of Lampyrinae such as Diaphanes nubilus Jeng and Lai, Pyrocoelia formosana Olivier, and $P$. prolongata have ever been recorded from localities at such high elevations in Taiwan (Jeng et al. 1999a, some of the species denoted as "sp." at that time). No living male of $P$. prolongata was found in or around the locality during the 3-day duration of our collecting trip, except for an already dead individual. This suggests that the mating season might have come to an end. At that time, a population of the species in central Taiwan (Anmashan, Taichung County, alt. $2300 \mathrm{~m}$ ) was in a peak season of activity (C.F. Lee, pers. comm.).

Behavioral remarks. A male of $P$. formosana collected from the same locality was put together with the female in a transparent plastic container to observe their interaction. At first the male did not show interest in the female. Later it attempted to copulate with the female but failed due to the female's resistance. They eventually copulated after one day of captivity. The male perished soon after copulation, while the female survived the following week and laid three or four eggs before she died. All eggs failed to hatch and decomposed. The female glowed in darkness via a pair of photogenic organs on abdominal sternite 8 . When wagging a finger around the female's head in a dusky environment, the female responded by powerfully raising her abdomen vertically to the body axis then laid down. It was found to be a one-to-one response after several repetitions. Apparently the female can detect the nearby moving subject and the action could be an intimidation to predators.

\section{Key to the females of Pyrocoelia species of Taiwan}

$1 \quad$ Elytral rudiments clearly extending beyond pronotum in width.................2

- Elytral rudiments short, not or slightly extending beyond pronotum in

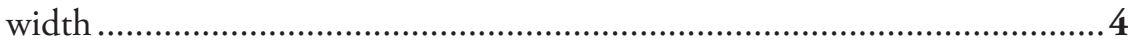

2 Elytral rudiments broad, lobe-like, extending posterolaterally and covering

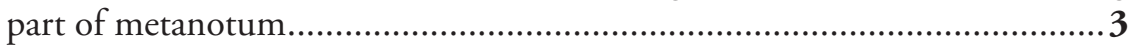


- $\quad$ Elytral rudiments narrow, sword-like, extending laterally and not covering any part of metanotum ..................................P. sanguiniventer Olivier

3 Elytral rudiments longer than broad by 1.5 times; mesoscutellum about as broad as long; pronotal windows ambiguous.......................P. analis (F.)

- $\quad$ Elytral rudiments longer than broad by 3 times; mesoscutellum transverse; pronotal windows clear ........................................ P. praetexta Olivier

4 Abdomen without morphologically recognizable photogenic organs; metanotum milky white; pronotum semicircular, translucent gray in explanate area...

P. formosana Olivier

- $\quad$ Abdomen with a pair of photogenic organs on sternite 8; metanotum bronze; pronotum more-or-less projecting forward, dark in margins and central carina between windows

P. prolongata Jeng and Lai

\section{Discussion}

The photogenic organs of females Pyrocoelia vary in number and position. Among the known taxa from Japan and Taiwan, $P$. analis, $P$. praetexta, $P$. rufa Olivier, $P$. miyako Nakane, and $P$. atripennis Lewis each have two pairs of morphologically recognizable lanterns on sternites 6 and 7 (Ohba 1983, 2004; Ho 1997, 2003; Chen 1999, 2003); $P$. prolongata has a significant pair on sternite 8 ; while $P$. formosana, $P$. sanguiniventer, $P$. discicollis Kiesenwetter, $P$. matsumurai Nakane, and $P$. abdominalis Nakane do not have visible lanterns if not glowing (Ohba 1993). However, females of P. praetexta are able to emit six spots of light on sternites $6-8$ and at least some species in the last group are confirmed to glow weakly in two spots on sternite 8 (Ho and Chu 2002; Chen 2003; Ohba 2004). It is therefore somewhat risky to interpret glowing behavior based solely on the external morphology of dead, and sometimes dried, specimens.

Both sexes of $P$. prolongata can emit green light from a pair of lanterns on sternite 8. The males are active during the daytime to locate mates by raising their heads and elevating the antennae in a V-shaped position, used to detect female pheromones, as observed for many other diurnal species (Ohba 1983, 1997a, 1997b, 2004). Occasionally they can be found at night owing to their bioluminescence. Ohba $(1983,2004)$ classified the diurnal species of Pyrocoelia from Japan into the CR system in which males find mates relying mainly on chemical signals and with the aid of relatively weak luminescent signals from mates over a short distance. However, the females of the diurnal species of Pyrocoelia, though able to glow, are extremely rarely seen in the field at night (Ohba 1983). The function of the female bioluminescence is thus questionable. Lall and Lloyd (1989) studied a day-active species, Lucidota luteicollis LeConte, and found that the electroretinographic sensitivity of the male (lamda-maximum $=530$ $\mathrm{nm}$ ) did not match its emission spectrum (lamda-maximum= $562 \mathrm{~nm}$ ). These authors concluded that the male does not rely on light signals to find a mate, and suggested that the flightless female might be the light receiver. The female could use the male bioluminescence to recognize a mate in the shady, dusky microhabitat in which such 
long-wavelength light can be transmitted more so than short wavelengths, and thus be detectable by the female. The bioluminescent spectrum and electroretinographic sensitivity of Pyrocoelia are scarcely studied except for a few cases (Eguchi et al. 1984; Ohmiya et al. 1996). The night-active P. miyako Nakane emits green light with a lambda-maximum at $550 \mathrm{~nm}$ by males (Ohmiya et al. 1996). The electroretinograph of P. atripennis Nakane, a day-active species from Japan, shows a broad green sensitivity with the lambda-maximum around $540 \mathrm{~nm}$ in the male (Eguchi et al. 1984). There is not yet any study on the bioluminescence and visual sensitivity in both sexes of a diurnal species of Pyrocoelia. Whether the bioluminescence is truly functional or merely an evolutionary residual remains open for future study.

\section{Acknowledgments}

We are grateful to the late Dr. M. Satô (1937-2006) for providing us the rare female specimen of $P$. prolongata available for this study. Thanks are also due to C.- $\mathrm{L}$. Li (Taiwan University, Taipei) and C.-F. Lee (Taiwan Agricultural Research Institute, Taichung) for their assistance during the collecting trip; and to H.-Y. Lee for photographs of the female of $P$. prolongata. This study was supported financially by the National Science Council of the Republic of China, grant Nr. NSC99-2621-M-002-027.

\section{References}

Chen TR (1999) An Ecological Guide to the Taiwanese Fireflies. Field Image Press, Taipei City, Taiwan, 191 pp. [In Chinese]

Chen TR (2003) The Fireflies of Taiwan. Field Image Press, Taipei City, Taiwan, 255 pp. [In Chinese]

Eguchi E, Nemoto A, Meyer-Rochow VB, Ohba N (1984) A Comparative study of the spectral sensitivity curves in three diurnal and eight nocturnal species of Japanese fireflies. Journal of Insect Physiology 30: 607-12.

Ho JZ (1997) The Lantern in the Dark-Firefly. Endemic Species Research Institute of Taiwan, Jiji Township, Taiwan, 131 pp. [In Chinese]

Ho JZ (2003) Rearing method and life cycle of Pyrocoelia analis (Coleoptera: Lampyridae). Bioformosa 38: 79-87.

Ho JZ, Chu JS (2002) Map for Firefly Watching in Taiwan. Morning Star Publishing Inc., Taichung City, Taiwan, 325 pp. [In Chinese]

Jeng ML, Lai J, Yang PS (1999a) A synopsis of firefly fauna at the six national parks of Taiwan. Chinese Journal of Entomology 19: 65-91. [In Chinese]

Jeng ML, Lai J, Yang PS, Satô M (1999b) On the validity of the generic name Pyrocoelia Gorham (Coleoptera, Lampyridae, Lampyrinae), with a review of Taiwanese species. Japanese Journal of Systematic Entomology 5: 347-362. 
Lall AB, Lloyd JE (1989) Spectral sensitivity of the compound eyes in two day-active fireflies (Coleoptera: Lampyridae: Lucidota). Journal of Comparative Physiology 166: 257-260.

McDermott FA (1966) Pars. 9: Lampyridae (2nd ed.). In: Steel WO (Ed) Coleopterorum Catalogus Supplementa. W Junk, s-Gravenhage, The Netherlands, 1-149.

Ohba N (1983) Studies on the communication system of Japanese fireflies. Science Report of the Yokosuka City Museum 30: 1-62, +6 pls.

Ohba N (1993) Rearing and Observation of Fireflies. Hot Press, Tokyo, Japan, 167 pp.

Ohba N (1997a) Competitive behavior of males of Pyrocoelia abdominalis in mating. Science Report of the Yokosuka City Museum 45: 39-44.

Ohba N (1997b) Mating behavior of Pyrocoelia matsumurai. Science Report of the Yokosuka City Museum 45: 45-50.

Ohba N (2004) Flash communication of Japanese fireflies. Integrative and Comparative Biology 44: 225-233.

Ohmiya Y, Hirano T, Ohashi M (1996) The structural origin of the color differences in the bioluminescence of firefly luciferase. FEBS Letters 384: 83-86. 
